\title{
Management of clandestine drug laboratories: need for evidence-based environmental health policies
}

\author{
Tamara A. Al-Obaidi - Stephanie M. Fletcher
}

Received: 6 July 2013/ Accepted: 10 August 2013/Published online: 4 September 2013

(C) The Japanese Society for Hygiene 2013

\begin{abstract}
Clandestine drug laboratories (CDLs) have been emerging and increasing as a public health problem in Australia, with methamphetamine being the dominant illegally manufactured drug. However, management and remediation of contaminated properties are still limited in terms of regulation and direction, especially in relation to public and environmental health practice. Therefore, this review provides an update on the hazards and health effects associated with CDLs, with a specific look at the management of these labs from an Australian perspective. Particularly, the paper attempts to describe the policy landscape for management of CDLs, and identifies current gaps and how further research may be utilised to advance understanding and management of CDLs and inform public health policies. The paper highlights a significant lack of evidence-based policies and guidelines to guide regulatory authority including environmental health officers in Australia. Only recently, the national Clandestine Drug Laboratory Guidelines were developed to assist relevant authority and specialists manage and carry out investigations and remediation of contaminated sites. However, only three states have developed state-based guidelines, some of which are inadequate to meet environmental health requirements. The review recommends well-needed intersectoral collaborations and further research to provide an evidence base for the development of robust policies and
\end{abstract}

\section{T. A. Al-Obaidi}

Independent Environmental Health Professional, Adelaide,

Australia

S. M. Fletcher $(\square)$

Faculty of Health, University of Technology, Sydney,

P.O. Box 123, Broadway, NSW 2007, Australia

e-mail: stephanie.fletcher@uts.edu.au standard operating procedures for safe and effective environmental health management and remediation of CDLs.

Keywords Clandestine drug laboratories · Australia . Environmental health practice $\cdot$ Research .

Evidence-based policy

\section{Background and introduction}

Clandestine drug laboratories, i.e. "the illicit production of drugs or drug precursors within an improvised laboratory environment" [1], have emerged as a public health problem in developed countries worldwide. According to a United Nations Office on Drugs and Crime (UNODC) [2] report, the majority of clandestine drug laboratories (CDLs) detected ( $\sim 99 \%$ ) manufactured amphetamine-type stimulants (ATS), with limited data available on the manufacturing of other forms of illicit drugs in illegal laboratories. This is similar to Australian trends, with pseudoephedrine and ephedrine being the most commonly used precursors in the production of methamphetamine within the ATS group [3]. The US National Drug Intelligence Center (NDIC) [4] defines a methamphetamine (also known as methylamphetamine or meth) laboratory as "an illicit operation that has the apparatus and chemicals needed to produce the powerful stimulant methamphetamine". The size and production ability of laboratories vary from large laboratories or "super labs" producing approximately $>10$ pounds $(\sim 4.5 \mathrm{~kg})$ of methamphetamine per production cycle to smaller "box labs" producing as little as an ounce ( $28.350 \mathrm{~g}$ ) or less [4].

Illegal production of methamphetamine has led to innovative use of space, resulting in laboratories being created in a variety of premises [5]. By-products of 
methamphetamine can be either volatile vapours which condense and become suspended in air as tiny particles [6, 7], or salts which persist on surfaces [8, 9]. Methamphetamine by-products can also persist on indoor surfaces for several months after production has ceased, particularly where there is no human activity or remediation [8]. Residual contamination of laboratories poses risks to human and environmental health $[10,11]$. It has been suggested that chronic or acute exposure to chemical components and/or by-products of methamphetamines may result in long-term health effects in both adults and toddlers and that disposal of hazardous waste from the "cooking" process can lead to harmful effects on the environment [11, $12]$.

Clandestine drug laboratories in Australia

Reports from the Australian media and relevant agencies suggest that illegal drug laboratories are on the rise, with methamphetamine being the dominant illegally manufactured drug in Australia [3, 13-15]. While Australia is not considered amongst the leading producers of illegal drugs, it was listed amongst the countries reporting the largest number of CDL detections in the 2010 World Drug Report, behind the USA and the Czech Republic [2]. This report indicates that many countries with lower detection rates only report large-scale laboratories [2]. The Australian Crime Commission (ACC) [3] reported that, during the 2010-2011 period, a record 703 CDLs were discovered, representing a $179 \%$ increase from the 252 identified in the 2001-2002 period. Table 1 indicates a gradual increase in the number of detections from 150 in 1999-2000 to 703 in 2010-2011. For the 2010-2011 period, all jurisdictions with the exception of Victoria and the Northern Territory reported an increase in CDL detections, and Queensland continued to have the highest number of detections, while Tasmania had the highest percentage increase ever recorded over the period [3].

Unfortunately, due to their illegal nature, these laboratories represent only a fraction of CDLs, which are often associated with explosions resulting in severe injury, contamination of the environment and destruction of property $[16,17]$. First responders, including law enforcement, fire and environmental health officers, are at serious risk from exposure to hazardous substances associated with drug production [15, 17, 18]. Reports from the USA suggest that, while meth events represent only a small proportion of acute hazardous substance-release events, they are more likely to result in injuries, accounting for more victims than non-meth events, with emergency first responders accounting for the majority of victims [19, 20]. The USA has made much headway in setting up regulatory and surveillance systems [4, 5, 21-23]; however there is limited regulation and direction in the management of clean-up of contaminated properties in Australia. A few clean-up/ remediation guidelines have been developed in Australia, but there is still limited understanding and clarity about the role of environmental health officers (EHOs) in the detection and remediation processes. Research is therefore needed for evidence-based planning and policy-making to guide safe detection and remediation of CDLs.

This review provides an update on the hazards and health effects associated with CDLs, looking specifically at the management of these labs from an Australian perspective. Specifically the paper attempts to describe the policy landscape for management of CDLs, and identifies gaps and how further research may be helpful to advance understanding and management of CDLs and inform public health policies. The paper highlights a significant lack of evidence-based policies and guidelines to guide EHOs in

Table 1 Number of clandestine laboratory detections in Australian states and territories, 2001-02 to 2010-11; source: Australian Crime Commission [3]

\begin{tabular}{|c|c|c|c|c|c|c|c|c|c|}
\hline Period & NSW & VIC & QLD & SA & WA & TAS & NT & ACT & Total \\
\hline 2001-2002 & 32 & 24 & 138 & 32 & 22 & 3 & 1 & 0 & 252 \\
\hline $2002-2003$ & 47 & 19 & 171 & 34 & 36 & 2 & 3 & 2 & 314 \\
\hline 2003-2004 & 61 & 20 & 189 & 48 & 33 & 1 & 6 & 0 & 358 \\
\hline 2004-2005 & 45 & 31 & 209 & 25 & 44 & 3 & 21 & 3 & 381 \\
\hline $2005-2006$ & 55 & 47 & 161 & 50 & 58 & 5 & 12 & 2 & 390 \\
\hline 2006-2007 & 49 & 72 & 132 & 51 & 37 & 9 & 1 & 5 & 356 \\
\hline 2007-2008 & 51 & 76 & 121 & 69 & 30 & 2 & 1 & 6 & 356 \\
\hline 2008-2009 & 67 & 84 & 148 & 65 & 78 & 0 & 7 & 0 & 449 \\
\hline 2009-2010 & 82 & 113 & 297 & 71 & 118 & 1 & 12 & 0 & 694 \\
\hline 2010-2011 & 87 & 63 & 293 & 75 & 171 & 11 & 2 & 1 & 703 \\
\hline
\end{tabular}

NSW New South Wales, VIC Victoria, QLD Queensland, SA South Australia, WA Western Australia, TAS Tasmania, NT Northern Territory, ACT Australian Capital Territory 
Australia and recommends further research to provide an evidence base for the development of robust policies and standard operating procedures based on safe and effective environmental health management and remediation of CDLs.

Health hazards and effects of CDLs

\section{(a) Health hazards associated with CDLs}

Illegal drug laboratories are not only a law enforcement challenge due to the illegal manufacture of controlled substances; they also have significant public health, safety and environmental impacts [24]. Illegal drug laboratoriesmainly for methamphetamine-come in various arrangements. Their location may vary from remote to rural, in residential and commercial premises including private homes, motels, hotels, apartments, house trailers, commercial buildings, abandoned buildings, campgrounds, mobile houses, trucks, trailers and different automobiles [5]. The cooking process may happen once or repeatedly using various production processes that utilise different reagents, forming a range of by-products [21, 25, 26]. Lab operators range from beginners with little or no chemistry knowledge to professional chemists with higher degrees [27]. Sizes of laboratories may also vary from small-scale, basic, temporary production to large-scale, highly complicated and technologically sophisticated "super labs". As a result, the nature and type of hazards generated vary immensely [4, 22].

According to the Society for Public Health Education (SOPHE) [29], likely hazards such as airborne contaminants, chemical spills, retained reagents, by-product waste, and contaminated surfaces and household items can be potentially harmful to future residents and remediation workers. Studies suggest that airborne contaminants including vapours and residues may disperse widely throughout buildings, permeate structures and can be deposited on furniture, carpets, insulation structures and household items in seized and active labs, posing short- and long-term health risks [6, 30]. Spills of liquid reagents, such as ammonia, ether, methanol and acetone, can potentially cause an airborne threat to the public due to the slow release of volatilized reagents [29].

Laboratory operators often indiscriminately dispose of hazardous waste, such as raw materials, toxic chemicals, carcinogens and phytotoxins, at on- and off-site locations, including household drains, large containers, backyards, soil, roads and creeks, resulting in not only significant health risks to the public and responders but also contamination of the environment [27, 29]. Pal et al. [25] indicated that, after the release of those chemicals into the environment, they may undergo various processes, such as sorption, degradation and leaching, in different environmental sections, resulting in potential harm to people, wildlife and ecosystems. Moreover, individuals, especially children, coming into contact with discarded waste may incur serious injuries [25, 26].

According to the Drug Enforcement Administration (DEA) [27], many children were present during illegal lab seizures nationwide in the USA in 2001, with many being exposed to toxic chemicals and others injured. Protection of children's health is paramount due to their vulnerability to environmental exposure compared with adults. Their active nature involving physical contact with their environment may increase their likelihood of being exposed to chemicals and contaminated environments through food, water and surfaces [22]. A New Zealand study found high prevalence of methamphetamine residue in hair samples from children, indicating evidence of passive exposure to methamphetamine [10]. The vulnerability of children to hazardous chemicals such as lead, asbestos and mercury utilised in drug production is another important consideration [22].

Other hazards associated with needles, syringes and glassware may put personnel at risk for infection with bloodborne diseases such as hepatitis B and human immunodeficiency virus (HIV)/acquired immunodeficiency syndrome (AIDS) [31]. This raises the issue of the need for appropriate personal protective equipment (PPE) and immunisation coverage for response personnel. Specific training may therefore be necessary for EHOs and other response personnel in the identification of CDL hazards and the use of appropriate exposure controls [12].

Another major hazard from CDLs is the risk of fires or explosions resulting from chemical reactions. The greatest risks are associated with active laboratories due to increased potential for exposure to precursor and reagent chemicals and their by-products [12, 15, 32]. This can threaten the health and safety of the illegal operators, innocent occupants of nearby rooms/premises and any persons who come into contact with the fumes [17]. Abandoned laboratories are thought to be less of a fire hazard, but they still pose a health risk to subsequent inhabitants of the affected premises. The risks are thought to be reduced in box labs despite potential risks from exposure to contaminated apparatus and volatile chemicals $[32,33]$

\section{(b) Health effects associated with CDLs}

The evidence base for the full spectrum of health effects from exposure to illegal drugs is still developing; however, exposure to chemicals used in drug production can be harmful [17]. Air-suspended methamphetamine particles can be inhaled and rapidly absorbed into the gas-exchange portion of the lung and thereby into the bloodstream [9]. 
The risk of this happening is highest immediately following production of the drug; as such, responders should be careful not to eat or smoke in the affected area [17]. Resuspension of chemicals is likely during seizure and removal of drug production equipment [8] and by walking or vacuuming of contaminated surfaces [9]. The US DEA [27] and Skeers [31] suggest that both acute and chronic health effects are presented by illegal drug laboratories, with various individuals usually at risk, including first responders, clean-up contractors, local health responders, residents in associated building(s), nearby residents, the public, property owners and subsequent tenants.

Law enforcement personnel and first responders can be exposed to various dangerous chemicals, such as those described in Table 2 [27, 31]. Response personnel should therefore be cognisant of the need for appropriate protective equipment. It is believed that chronic exposure to aerosolized chemical particulates can have detrimental health effects including cancer, birth defects, reproductive disorders and injury to the nervous system, kidneys and liver [34]. Children may be particularly susceptible to CDL toxicity, with some reports suggesting that children have been found in an estimated $20 \%$ of meth laboratories [20]. A surveillance report indicated that 13 children were injured due to exposure to lethal substances, such as anhydrous ammonia, in about eight reported meth events [35]. It has been reported that neonatal death and blindness, physical malformations, behavioural problems and lower intelligence test scores in children have been attributed to use of amphetamines and methamphetamines by pregnant women [9].

Table 2 Examples of frequently used chemicals and associated hazards in illegal drug (meth) production; source: Hannan [28]

\begin{tabular}{|c|c|c|}
\hline Chemical & Example of source & $\begin{array}{l}\text { Hazard property } \\
\text { (hazard class) per } \\
\text { DOT regulations }\end{array}$ \\
\hline $\begin{array}{l}\text { Petroleum } \\
\text { (toluene, } \\
\text { xylene, } \\
\text { ether) }\end{array}$ & $\begin{array}{l}\text { Toluol; xylol; starting fluid } \\
\text { (ether); Coleman camping } \\
\text { fuel (mixture of petroleum } \\
\text { solvents) }\end{array}$ & $\begin{array}{l}\text { Flammable liquids } \\
\text { (3) }\end{array}$ \\
\hline $\begin{array}{l}\text { Sodium } \\
\text { hydroxide }\end{array}$ & Red Devil Lye & Corrosive base (8) \\
\hline Sulphuric acid & Draino & Corrosive acid (8) \\
\hline $\begin{array}{l}\text { Hydrochloric } \\
\text { acid }\end{array}$ & Muriatic_pool cleaner & Corrosive acid (8) \\
\hline Lithium & Lithium batteries & $\begin{array}{l}\text { Dangerous when } \\
\text { wet (4.3) }\end{array}$ \\
\hline $\begin{array}{l}\text { Red } \\
\text { phosphorus }\end{array}$ & Matchbox strike plates & $\begin{array}{l}\text { Flammable solid } \\
\text { (4.1) }\end{array}$ \\
\hline Iodine & Pharmaceuticals & Corrosive (8) \\
\hline $\begin{array}{r}\text { Anhydrous } \\
\text { ammonia }\end{array}$ & Agriculture cooperative & $\begin{array}{l}\text { Poisonous gas } \\
(2.3)\end{array}$ \\
\hline
\end{tabular}

DOT Department of Transportation
The US Hazardous Substances Emergency Events Surveillance (HSEES) system, which monitors the public health consequences of acute hazardous substance-release events [21], reported that, during the January 2000 to June 2004 period, 1,791 (4\%) of the 40,349 events reported were associated with illicit meth production. Of these, 558 (31\%) events resulted in 947 injured persons, more than half of whom were police officers. Frequent symptoms/ injuries included respiratory irritation $(39 \%)$, headache (26\%), eye irritation ( $8 \%$ ) and burns ( $8 \%$ ), nearly half of which required either on-site treatment or hospitalisation [20].

Witter et al. [36] found that more than $70 \%$ of law enforcement personnel investigating methamphetamine labs reportedly experienced headaches, respiratory symptoms, central nervous system symptoms, sore throat and other symptoms. Although symptoms diminished after a short time period for some individuals, others required medical attention for persistent symptoms [36]. An earlier retrospective cohort study found that 59 law enforcement personnel surveyed in Washington State experienced headaches and respiratory, mucous and skin irritations, mostly during the processing phase of removing laboratory chemicals and taking samples [32]. Life-threatening symptoms due to severe exposure may also occur, leading to respiratory failure, coma and death depending on routes of exposure, duration and compound type [31].

Due to the risks and hazards associated with investigation and remediation of CDLs, response personnel including EHOs should be provided with full personal protective equipment (PPE), which must be decontaminated immediately upon exiting the lab [17]. Experts suggest that selfcontained breathing apparatus (SCBA) or respirator, and level $\mathrm{B}$ personal protective suits are the minimum protection required, and level A protection can be used where a higher level of skin protection is required [17].

\section{Management of illegal drug labs in Australia}

In Australia, the issue of illegal drug supply and use has been addressed by the National Drug Strategy, which is a joint venture between the Commonwealth of Australia, state/ territory governments and the non-governmental sector [37]. One of the main aims of this strategy is to provide a national framework to minimise health, social and economic harms to communities caused by illegal drugs, through supply reduction, demand reduction and harm reduction [37]. An additional objective of the strategy is to reduce harm caused by CDLs through improving community and workforce knowledge of lab risks and the requirement for site remediation [37]. To implement this objective of the strategy, the Attorney-General's Department and the Australian Crime Commission in collaboration with other 
agencies developed a national guidance document in 2011 to address the management of CDLs [38]. These Clandestine Drug Laboratory Guidelines are intended only as a framework to assist relevant authority and specialists manage and carry out investigations and remediate sites contaminated by illegal operations of drug laboratories [38]. Under these guidelines, after police and forensic chemists seize a laboratory, process and determine safety, they will provide notifications and a "site assessment report" to relevant state/territory regulatory authority (including EHOs) (Fig. 1).

Without directly specifying the professionals involved, the guidelines advise that responsible officers/units within those authority should undertake the following general steps after notification and site clearance by police [38]:

- "Conducting preliminary assessments in relation to contamination of sites and their suitability for habitation. This should include outdoor (environment/health assessment) and indoor (health assessment). It is recommended that Officers attend sites while police are still investigating and if attending that they should ensure their own safety and wear proper relevant protective equipment (PPE). It is also stated that officers should ideally be aware of the nature and types of chemicals present and should have access to the full
Fig. 1 General process for site investigation and reporting under the Australian Government Clandestine Drug Laboratory Remediation Guidelines (sourced from Newell et al. [38]). The figure shows the four phases in the notification and remediation process that are recommended to be followed by the various agencies involved in clandestine drug laboratory remediation
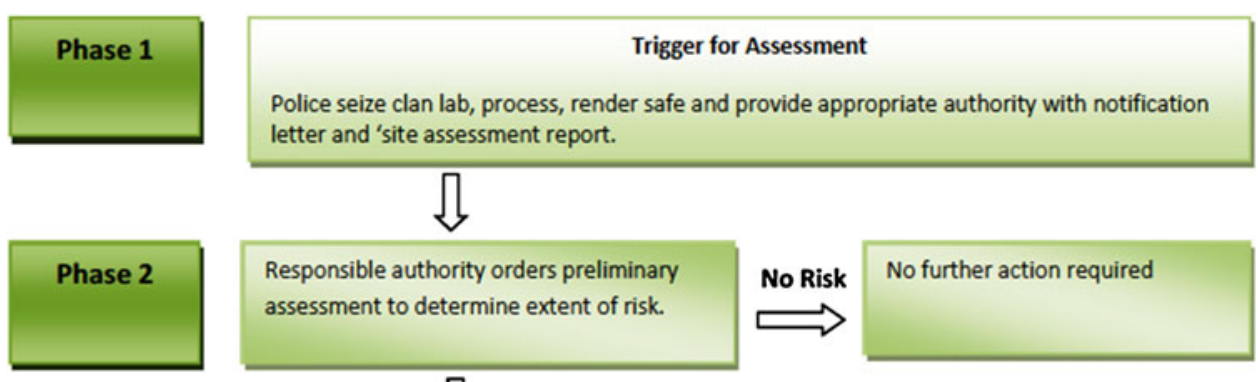

Risk Identified

Investigation and Assessment checklist indicates contamination is present/potentially present.
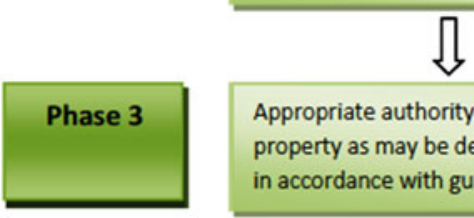

Appropriate authority issues pollution control/prohibition or other environmental order against property as may be deemed necessary. Authority issues order to provide contamination order in accordance with guideline.

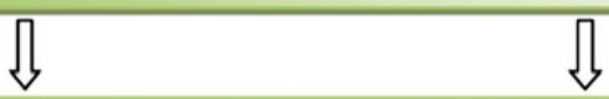

Completion of site assessment checklist and investigation, including laboratory analysis, in accordance with guideline.

\section{Contamination Identified}

Assessment confirms contamination. Remediation Action Plan (RAP) is devised. Responsible authority initiates remediation.

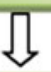

On completion of remediation activity, a site validation report is prepared.
No Contamination Identified

Responsible authority reviews investigation report.

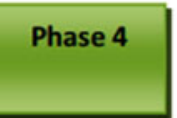

Al-Obaidi
Appropriate authority reviews report and audits checklist, issues site clearance on acceptance of final validation report. 
information regarding those chemicals and manufacturing processes while conducting this assessment.

- If risk is found, imposing contamination control, cleanup notices, environmental orders and determining who is responsible for the assessment and remediation of sites. The guidelines state that these actions should be determined by the policies and practices developed by each state/territory regulatory authority.

- If further assessment and remediation are necessary then authority should either:

- Appoint the services of a properly competent person which include EHOs with an environmental health degree.

- Oblige property owners or any person who have legal authority over the site to provide evidence that the site will not create a health or environmental health risks. This includes appointing a consultant that should follow proper site investigations, reporting and remediation and reporting back to the authority".

As stated in the document's introduction, these guidelines are targeted towards regulatory authority and environmental professionals. Therefore, it is assumed that "regulatory authority" - which administer health and/or environmental legislation and which take actions to protect health and prevent environmental contamination-also include health departments, environment protection agencies and councils, while responsible officers are EHOs and/ or environment officers. That being said, use of these guidelines is limited to administration and remediation of contaminated sites, and the Australian Government recommends using them in conjunction with other endorsed guidelines [38]. Unfortunately, there are little or no other endorsed guidelines available in Australia. Moreover, the guideline's disclaimer states that anybody using the document should ask for specialist guidance to establish if the guidelines are relevant to their individual conditions. Also, the guidelines do not make any expressed or implied liability or warranty [38].

This guideline was developed fairly recently, and as such few states or territories have been able to develop guidelines or policies relevant to management of these laboratories, which are generally very basic. In fact, only three Australian states have developed documentation on the subject, some with little or no reference to the roles of EHOs. Table 3 summarises the contents of these three available documents with respect to key aspects of management of CDLs and the roles and responsibilities of EHOs.

In Western Australia (WA), the Department of Health (WA Health) in collaboration with the Department of Environment and Conservation (DEC), WA Police,
ChemCentre of WA and Department of Housing developed interim guidelines in 2012 to address the notification process between WA Police, WA Health, DEC and local government (LG) as well as the assessment and site management of CDLs [39]. The general notification process of illegal drug labs in WA is shown in Fig. 2.

According to these interim guidelines, EHOs play a significant role once they receive notification by WA Police and are expected to undertake referrals, investigations, reporting and follow-up (Fig. 2). The temporary guidelines address the level of responsibility of EHOs, whether from WA Health, local governments or DEC, and indicates that their main purpose is to provide local government EHOs and other regulators with accurate advice regarding reporting, and management of public health and environmental risks, as well as to advise on the location and characteristics of illegal drug labs [39]. The document also refers to the specific sections of WA public health and environmental legislation to be followed by local governments and DEC. It also includes details on management of different types of laboratories in accordance with the ChemCentre and WA Police reports as well as general guidance on remediation, validation and personal safety for officers to consider and follow while responding to CDLs [40]. However, several issues have been raised more recently by WA Health regarding the implementation process of these guidelines and their effect on local government EHO roles, which can be guided by further research. These include [39]:

- Notification to receival process

- Continuous engagement of relevant agencies in the process

- Technical information and resources available, such as approvals

- Level of enforcement by EHOs

- Adequacy of legislation, such as the Health Act 1911

- Residential versus industrial and occupational versus non-occupational settings issues, as the guidelines are only intended for non-occupational and residential settings

These are only temporary guidelines, and WA Health in collaboration with other regulatory agencies is in the process of developing more detailed guidelines as well as a training package for EHOs to go along with the release of the new technical guidelines in 2013 [39].

In Victoria, a Practice Note on Clandestine Laboratory Remediation was developed by the Victoria Department of Health in 2012. It is the only document found to address CDL management, and it is developed mainly for local government EHOs to assist them in managing health hazards related to remediation of laboratories [41]. The practice note also refers to the national guidelines (discussed 
Table 3 Summary of key areas of management of illegal drug laboratories and the roles and responsibilities of EHOs in Western Australia, Victoria and Queensland

\begin{tabular}{|c|c|c|c|}
\hline $\begin{array}{l}\text { Key areas of } \\
\text { clandestine } \\
\text { laboratory } \\
\text { management }\end{array}$ & $\begin{array}{l}\text { Roles, Responsibilities \& Issues } \\
\text { Relevant to Environmental Health } \\
\text { Officers in Western Australia (WA } \\
\text { Health, 2012) }\end{array}$ & $\begin{array}{l}\text { Roles, Responsibilities \& Issues } \\
\text { Relevant to Environmental Health } \\
\text { Officers in Victoria (Victoria } \\
\text { Department of Health, 2012) }\end{array}$ & $\begin{array}{l}\text { Roles, Responsibilities \& Issues } \\
\text { Relevant to Environmental Health } \\
\text { Officers in Queensland (Queensland } \\
\text { Health, 2012) }\end{array}$ \\
\hline $\begin{array}{l}\text { Document } \\
\text { relevance }\end{array}$ & $\begin{array}{l}\text { Developed for relevant authority (local } \\
\text { governments and DEC) and specifies } \\
\text { roles of EHOs from relevant authority }\end{array}$ & $\begin{array}{l}\text { Developed mainly for local } \\
\text { government EHOs }\end{array}$ & $\begin{array}{l}\text { Owners of properties where illegal } \\
\text { drug activities or laboratory took } \\
\text { place }\end{array}$ \\
\hline $\begin{array}{l}\text { Clandestine lab } \\
\text { hazards }\end{array}$ & $\begin{array}{l}\text { - Outlines two distinct possible risks: } \\
\text { dwelling contamination and } \\
\text { environmental contamination }\end{array}$ & $\begin{array}{l}\text { - Recognises potential risks to health } \\
\text { and the environment }\end{array}$ & $\begin{array}{l}\text { - Mentions potential health and } \\
\text { environmental hazards }\end{array}$ \\
\hline $\begin{array}{l}\text { Links to national } \\
\text { guidelines }\end{array}$ & $\begin{array}{l}\text { - Investigation levels (IL) developed by } \\
\text { the national guidelines are used as } \\
\text { basis for risk-based analysis and } \\
\text { remediation }\end{array}$ & $\begin{array}{l}\text { - Investigation levels (IL) developed } \\
\text { by the national guidelines are used as } \\
\text { basis for risk-based analysis }\end{array}$ & $\begin{array}{l}\text { - The national guidelines are included } \\
\text { as a useful link to consider, but does } \\
\text { not provide explanation on their use } \\
\text { and relevance }\end{array}$ \\
\hline $\begin{array}{l}\text { EHO safety and } \\
\text { use of PPE }\end{array}$ & $\begin{array}{l}\text { - EHO safety and use of PPE are } \\
\text { discussed. Guidelines on PPE use are } \\
\text { based on national guidelines }\end{array}$ & $\begin{array}{l}\text { - EHO safety briefly outlined with } \\
\text { respect to responding to nuisance } \\
\text { caused by clandestine labs } \\
\text { - No instructions on PPE or other } \\
\text { safety measures provided }\end{array}$ & $\begin{array}{l}\text { - Only indicates that owners must } \\
\text { contact Queensland Health regarding } \\
\text { potential health risks but does not } \\
\text { provide detailed guidance for EHOs }\end{array}$ \\
\hline $\begin{array}{l}\text { Link to } \\
\text { legislation }\end{array}$ & $\begin{array}{l}\text { - Health Act 1911: sections (general } \\
\text { powers, issuing notices, dwelling } \\
\text { suitability, and remediation) relevant } \\
\text { to EHO roles and legal proceedings are } \\
\text { discussed } \\
\text { - Environmental Protection Act } 1986 \\
\text { and Contaminated Sites Act 2003: } \\
\text { sections relevant to LG EHOs and } \\
\text { DEC officers are discussed }\end{array}$ & $\begin{array}{l}\text { - Public Health and Wellbeing Act } \\
2008 \text { (PHWA): nuisance and powers } \\
\text { sections } \\
\text { - Municipal Association of Victoria's } \\
\text { PHWA Guidance Manual for Local } \\
\text { Government Authorised Officers: } \\
\text { nuisance, investigation and } \\
\text { enforcement mechanism and } \\
\text { procedures sections }\end{array}$ & $\begin{array}{l}\text { - Public Health Act } 2005 \text { is to be used } \\
\text { by local government in relation to } \\
\text { health risks from former clandestine } \\
\text { labs } \\
\text { - No explanation on which sections to } \\
\text { be used, who is authorized to enforce } \\
\text { them and when they are enforced }\end{array}$ \\
\hline $\begin{array}{l}\text { Notification and } \\
\text { initial follow- } \\
\text { up }\end{array}$ & $\begin{array}{l}\text { - Police to WA Health to LGs and DEC } \\
\text { - Role of EHOs clearly outlined and } \\
\text { discussed, including their roles in } \\
\text { access to sites, reporting and } \\
\text { inspections }\end{array}$ & - Role of LG EHOs discussed & $\begin{array}{l}\text { - QLD Police to notify property } \\
\text { owners } \\
\text { - Role of EHOs, property } \\
\text { - Access and safety considerations not } \\
\text { clearly outlined }\end{array}$ \\
\hline $\begin{array}{l}\text { Roles in } \\
\text { remediation }\end{array}$ & $\begin{array}{l}\text { - EHOs are directly involved in the } \\
\text { assessment and management of sites } \\
\text { - LG EHOs to issue notices, determine } \\
\text { management steps, contacting, } \\
\text { directing and liaising with owners } \\
\text { - Owners to engage forensic and } \\
\text { cleaning contractors at the request of } \\
\text { LG EHOs } \\
\text { - EHO roles where owners are not } \\
\text { located are unclear } \\
\text { - EHO roles in industrial and } \\
\text { occupational sites are not discussed }\end{array}$ & $\begin{array}{l}\text { - EHOs are not to be involved in } \\
\text { assessment, testing or remediation, } \\
\text { which is deemed the responsibility of } \\
\text { owners } \\
\text { - EHO to assist owners in engaging } \\
\text { qualified assessors for further } \\
\text { assessment, investigation and } \\
\text { remediation; issue improvement and } \\
\text { prohibition notices if required; agree } \\
\text { on remediation plans; and oversee } \\
\text { the remediation process } \\
\text { - EHO roles in industrial and } \\
\text { occupational sites and where owners } \\
\text { are not located are unclear }\end{array}$ & $\begin{array}{l}\text { - Owners are responsible for } \\
\text { assessment, investigation and } \\
\text { remediation of sites } \\
\text { - Owners to engage the services of an } \\
\text { experienced cleaning company or a } \\
\text { professional to manage the process; } \\
\text { may follow the US EPA Voluntary } \\
\text { Guidelines for Methamphetamine } \\
\text { Laboratory Clean Up to clean } \\
\text { properties themselves. The role of } \\
\text { EHOs in verifying effectiveness of } \\
\text { remediation is not discussed }\end{array}$ \\
\hline
\end{tabular}


Table 3 continued

\begin{tabular}{|c|c|c|c|}
\hline $\begin{array}{l}\text { Key areas of } \\
\text { clandestine } \\
\text { laboratory } \\
\text { management }\end{array}$ & $\begin{array}{l}\text { Roles, Responsibilities \& Issues } \\
\text { Relevant to Environmental Health } \\
\text { Officers in Western Australia (WA } \\
\text { Health, 2012) }\end{array}$ & $\begin{array}{l}\text { Roles, Responsibilities \& Issues } \\
\text { Relevant to Environmental Health } \\
\text { Officers in Victoria (Victoria } \\
\text { Department of Health, 2012) }\end{array}$ & $\begin{array}{l}\text { Roles, Responsibilities \& Issues } \\
\text { Relevant to Environmental Health } \\
\text { Officers in Queensland (Queensland } \\
\text { Health, 2012) }\end{array}$ \\
\hline $\begin{array}{l}\text { Environmental } \\
\text { contamination }\end{array}$ & $\begin{array}{l}\text { - WA DEC officers to respond to } \\
\text { external environmental contamination. } \\
\text { DEC to liaise with LG EHOs and } \\
\text { decide on proper follow-up and } \\
\text { statutory actions } \\
\text { - DEC pollution and contaminated sites } \\
\text { branches to manage protection of the } \\
\text { environment and contamination issues } \\
\text { - Owners to engage environmental } \\
\text { contractors in accordance with DEC } \\
\text { instructions and directions }\end{array}$ & $\begin{array}{l}\text { - Assessed by contracted assessors } \\
\text { - Environment Protection Agency } \\
\text { (EPA) Victoria to advise on } \\
\text { transportation, disposal and landfill } \\
\text { facilities } \\
\text { - Relevant legislation and role of EPA } \\
\text { Victoria in the process are not } \\
\text { discussed }\end{array}$ & $\begin{array}{l}\text { - No explanation on: agencies to report } \\
\text { to and to be involved, EHO roles, } \\
\text { owner's responsibilities, who to } \\
\text { contact if contamination is found and } \\
\text { legalisation enforcement }\end{array}$ \\
\hline $\begin{array}{l}\text { Post-remediation } \\
\text { assessment }\end{array}$ & $\begin{array}{l}\text { - LG EHOs and DEC officers to verify } \\
\text { compliance with legislation and } \\
\text { notices using the forensic and } \\
\text { environmental contractors' written } \\
\text { report }\end{array}$ & $\begin{array}{l}\text { - LG EHOs to verify compliance with } \\
\text { notices using assessor's written } \\
\text { reports }\end{array}$ & $\begin{array}{l}\text { - Test kits to be used by owners to } \\
\text { verify effectiveness of cleaning and } \\
\text { remediation, with the assistance of } \\
\text { the Queensland Health Forensic and } \\
\text { Scientific Services }\end{array}$ \\
\hline $\begin{array}{l}\text { Training on } \\
\text { management } \\
\text { and the use of } \\
\text { documents } \\
\text { discussed }\end{array}$ & $\begin{array}{l}\text { - Information sessions on the interim } \\
\text { guidelines and their use are being } \\
\text { provided to LG EHOs. A training } \\
\text { package for EHOs will be released in } \\
2013\end{array}$ & - Not discussed & - Not discussed \\
\hline
\end{tabular}

PHWA Public Health and Wellbeing Act, $L G$ local government, DEC Department of Environment and Conservation

earlier) to be used by EHOs if general and more detailed information is needed. In general, the flowchart in Fig. 3 (reproduced from the practice note) outlines the process to be followed by EHOs in remediating CDL sites and shows the roles and responsibilities of local government EHOs in the process.

According to this document and flow chart, it is evident that local government EHOs are neither expected nor recommended to personally assess, test or remediate a CDL location under the public health legislation [41]. Instead, it is stated that only experienced professionals in this field should carry out these responsibilities with proper engagement and overseeing by local government EHOs. Local government EHOs can also advise property owners, who are considered to have the full responsibility for remediating sites, by providing contact details of properly competent assessors and cleaning contractors [41]. In addition, the practice note does not provide any information about the responsibilities or roles of EHOs from the Department of Health or the Environment Protection Agency regarding this issue.

In Queensland, only a fact sheet in relation to the management of CDLs was found, released by the Queensland Department of Health (Queensland Health) in 2012. The purpose of this fact sheet is to give general advice to owners of dwellings which had illegal drug laboratories [42]. This document is therefore not intended to provide guidance on the roles and responsibilities of EHOs within different regulatory authority. According to this fact sheet, the responsibility for property assessment, investigation and remediation lies solely with property owners, who must ensure that the property is safe for future residents. The document does not clearly define what safe property means, with no reference to standards or investigative numbers. The fact sheet also mentions briefly that local governments regulate health risks from previous CDLs under the Public Health Act 2005 and that other regulators may also be involved, including regulators who deal with hazardous waste generated from these labs. Moreover, when further information is needed regarding health hazards generated from illegal drug laboratories, it is advised that Queensland Health be contacted for advice. However, the fact sheet provides no discussion on the roles of regulatory authority, the degree of their involvement and follow-up regarding this issue, public health response or legislative requirements and enforcement.

Based on the foregoing, it is evident that the policy landscape for management of CDLs in Australia is limited and still under-developed with respect to providing adequate guidance for EHOs and other regulatory authority involved in management and remediation of CDLs. While the Commonwealth of Australia has recently provided broad guidelines, the majority of state and territory jurisdictions are yet to provide clear, unambiguous directives for EHOs. Research is needed to provide the evidence base 


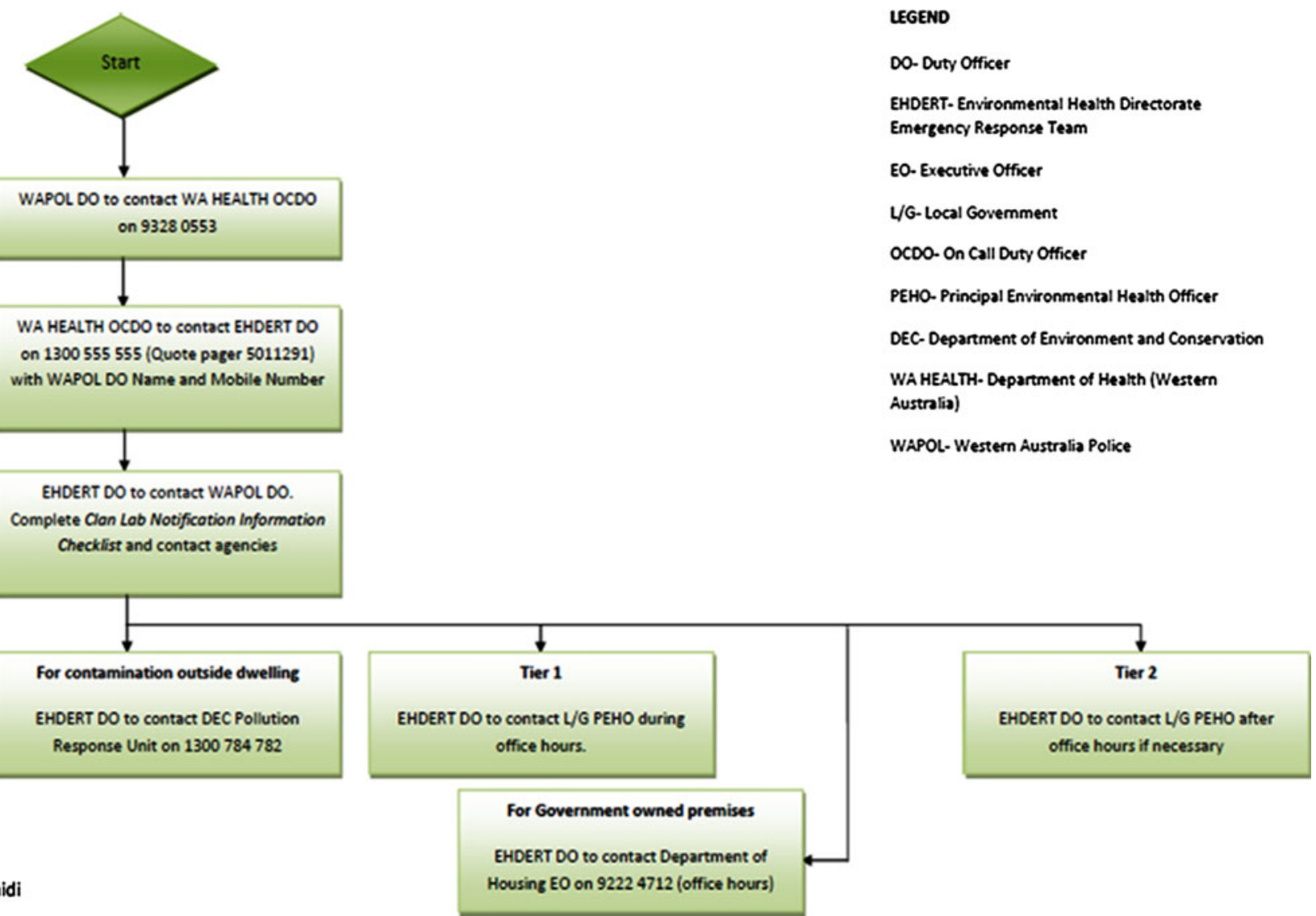

Fig. 2 Flowchart of the notification process of illegal drug laboratories in Western Australia (sourced from WA Health [39]). The figure shows that the procedure begins with notification by the

for the development of context-specific policies and guidelines to facilitate multi-disciplinary and collaborative CDL management.

\section{Current research on CDLs}

There is little or no research in the published literature pertaining to occupational, safety and health exposure and handling of CDLs in Australia. The limited availability of robust policies for management of CDLs in Australia may be a reflection of the limited research being conducted in this area. The research being conducted in Australia focusses on the law enforcement aspects, health effects, outcomes of illicit drug use and sports-related use of controlled substances. The Illicit Drug Data Report 2009-2010 indicated that illicit drug data were obtained from a variety of sources, such as law enforcement, health and academia. However, the evidence base that is provided from these sources was mainly intended to assist decision-makers in the development of strategies to combat the threat posed by illicit drugs [14], but this does not necessarily translate to
Western Australia Police and also outlines what is to be done for tier 1 (during office hours) and tier 2 (outside of office hours) notifications

assisting those on the front line. A dated report on the proceedings of a one-day research workshop hosted by the Australian National University in 1993 examined "Australian research on the structure and economics of drug markets, the interaction of drug markets and law enforcement and the impact of drug markets on health" [43]. The majority of studies presented at that time surrounded the law enforcement aspects and the public health risk of amphetamine use [43]. One of the key recommendations from the workshop was that "Research should be able to evaluate the effectiveness of interventions and policies and to predict likely effects of new policies" [43]. The workshop recommendations made over a decade ago remain as relevant today as they were then.

Conclusions and scope for future research

This review has found that, whilst CDLs are an emerging environmental health issue in Australia, several gaps in policy and guidelines were identified, indicating a strong need for rigorous research. There is sufficient evidence 


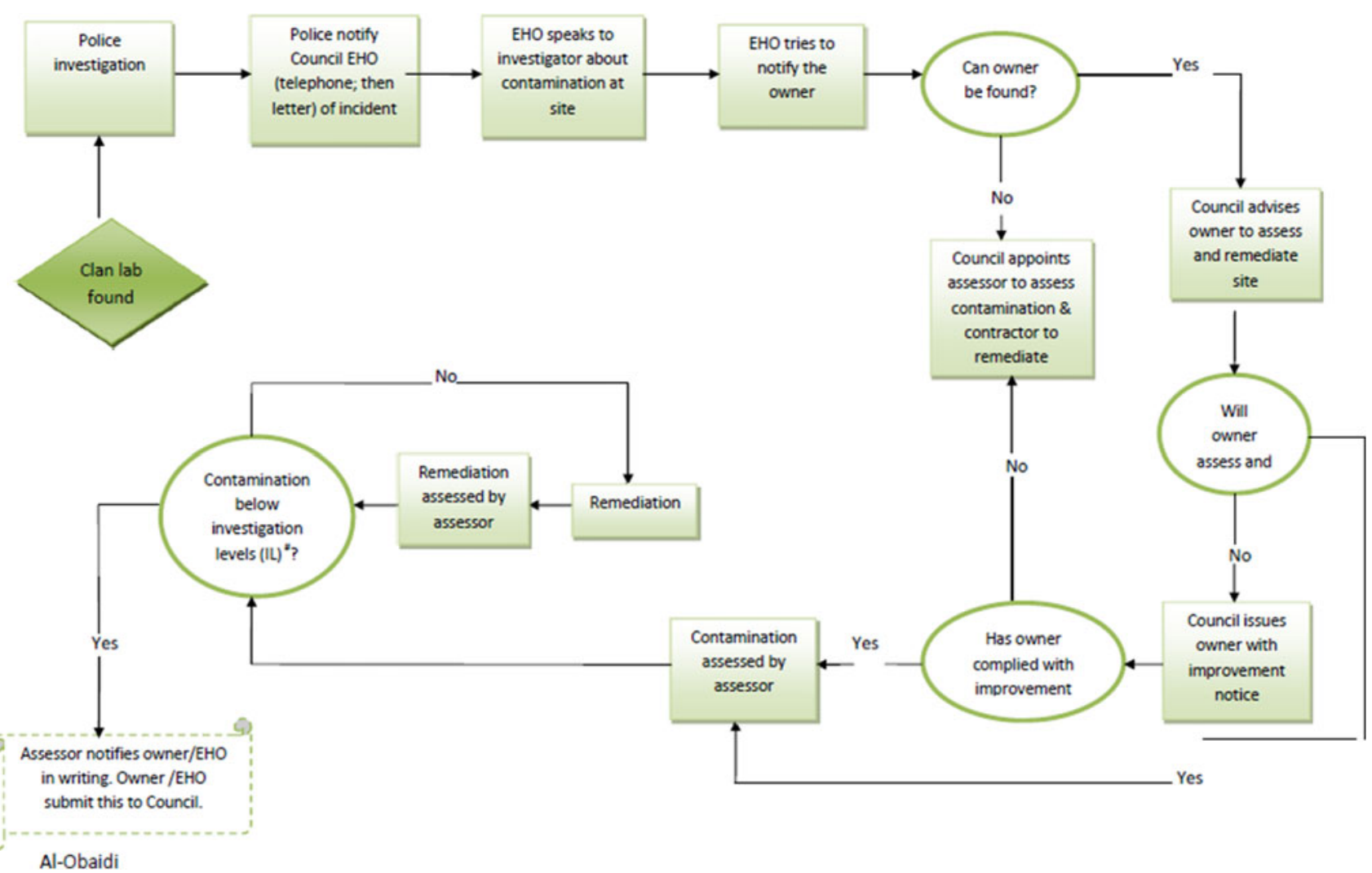

Fig. 3 Victoria Department of Health flow chart for remediation of clandestine drug laboratory sites (sourced from Victoria Department of Health [41]). The flow chart outlines the Victoria Department of

from the discussion to indicate that research is needed at the local level to inform the development of effective interventions and policies for management of CDLs in Australia. Research could determine whether specific guidelines are needed for each state or at federal level for adaption at state level. Research could help to define what proportion of CDLs are being missed and the burden of illness associated with exposure to CDLs. Research is needed to determine whether EHOs or other regulatory personnel are adequately trained and equipped to respond to CDLs. This would include: whether adequate standard operating procedures are in place and being followed; whether adequate and appropriate personal protective equipment is provided; reporting requirements and followup procedures; safe handling, re-use and/or disposal of PPE; and pre- and post-exposure testing to determine whether response personnel are exposed to harmful levels of harmful chemicals. Additional field research could assist in providing evidence of the effectiveness of remediation procedures in minimizing exposure of future occupants of premises used for meth production, and to provide more specific recommendations for remediation protocols.

Additional considerations should be given to other occupational, safety and health issues that need to be
Health procedures, general roles of EHOs, other agencies and property owners and the decision-making process for remediation of clandestine drug laboratory sites

considered and addressed by local councils, state and federal health sectors, including whether EHOs and other regulatory personnel should be immunised against potentially infectious material they may encounter in drug premises. Other issues have been identified, including the need for clarification of the illicit drugs research sector to enable access to funding, since it does not seem to fit clearly into either "health" or "law enforcement" research funding priorities. There is much room for inter-sectoral research collaboration, which should be given priority funding. Specific training should be provided for EHOs and other response personnel in identification of CDL hazards and use of appropriate exposure controls.

Conflict of interest The authors declare that they have no conflict of interest.

\section{References}

1. Newell P. Clandestine drug manufacture in Australia. Chem Aust. 2008;75:11-4.

2. UNODC. World Drug Report 2010. New York: United Nations Office on Drugs and Crime (UNODC). 2010.

3. ACC. Illicit Drug Data Report 2010-11. Canberra City: Australian Crime Commission. 2012. 
4. NDIC. Methamphetamine Laboratory Identification and Hazards: Fast Facts. National Drug Intelligence Center (NDIC), US Department of Justice. 2004.

5. Granholm JM, Olszewski J. Cleanup of Clandestine Drug Laboratory guidance. Michigan: Michigan Department of Community Health; 2007.

6. Martyny JW, Arbuckle SL, McCammon CS, Esswein EJ, Erb N, et al. Chemical concentrations and contamination associated with clandestine methamphetamine laboratories. J Chem Health Saf. 2007;1:40-52.

7. Salocks CB, Hui X, Lamel S, Qiao P, Sanborn JR, et al. Dermal exposure to methamphetamine hydrochloride contaminated residential surfaces: surface $\mathrm{pH}$ values, volatility, and in vitro human skin. Food Chem Toxicol. 2012;50:4436-40.

8. Environmental Risk Sciences. Derivation of risk-based investigation levels: Clandestine Drug Laboratory. Site Investigation Guidelines Australian Crime Commission. 2009.

9. VanDyke M, Erb N, Arbuckle S, Martyny J. A 24-hour study to investigate persistent chemical exposures associated with clandestine methamphetamine laboratories. J Occup Environ Hyg. 2009;6:82-9.

10. Bassindale T. Quantitative analysis of methamphetamine in hair of children removed from clandestine laboratories-evidence of passive exposure? Forensic Sci Int. 2012;219:179-82.

11. AGNMI. Clandestine drug laboratories 2012. Australia: Australian Government National Measurement Institute. 2012.

12. Cameron M. Health and safety concerns for law enforcement personnel investigating clandestine drug labs. Chem Health Saf. 2002;9:6-9.

13. ACC. Illicit Drug Data Report 2008-09. Canberra City: Australian Crime Commission. 2010.

14. ACC. Illicit Drug Data Report 2009-10. Canberra City: Australian Crime Commission. 2011.

15. Caldicott DGE, Pigou PE, Beattie R, Edwards JW. Clandestine drug laboratories in Australia and the potential for harm. Aust $\mathrm{N}$ Z J Public Health. 2005;29:155-62.

16. Barn P, Wiens M, Dods P. Clandestine amphetamine-derived drug laboratories: remediation guidelines for residential settings. 2012.

17. Smith JP (2011) Clandestine drug labs. Firehouse. Fort Atkinson, United States, Fort Atkinson: Cygnus Business Media, Inc. p. 22-29.

18. McKetin R, McLaren J, Kelly E. The Sydney methamphetamine market: patterns of supply, use, personal harms and social consequences. National Drug Law Enforcement Research Fund. 2005.

19. Cooper D, Souther L, Hanlon D, Fischer P, Leiker R, et al. Public health consequences among first responders to emergency events associated with illicit methamphetamine laboratories selected states, 1996-1999. Morb Mortal Wkly Rep. 2000;49:X-1024.

20. Cooper D, Rice N, Wilburn R, Horton DK, Rossiter S. Acute public health consequences of methamphetamine laboratories16 states, January 2000-June 2004. MMWR. 2005;54:356-9.

21. Melnikova N, Welles WL, Wilburn RE, Rice N, Wu J, et al. Hazards of illicit methamphetamine production and efforts at reduction: data from the hazardous substances emergency events surveillance system. Public Health Rep. 2011;126:116-23.

22. US EPA. Voluntary Guidelines for Methamphetamine Laboratory Cleanup. United States Environmental Protection Agency. 2013.

23. Welles WL, Wilburn RE, Ehrlich JK, Kamara JM. New York Hazardous Substances Emergency Events Surveillance (HSEES) data support emergency response, promote safety and protect public health. J Loss Prev Process Ind. 2009;22:728-34.
24. Cline JS. Illegal Methamphetamine Laboratories as a public health hazard. UNC School of Government. 2005.

25. Pal R, Megharaj M, Kirkbride KP, Naidu R. Illicit drugs and the environment. Hobart, Tasmania: National Drug Law Enforcement Research Fund (NDLERF). 978-0-9807169-4-8 978-09807169-4-8. 2008.

26. Pal R, Megharaj M, Kirkbride KP, Naidu R. Illicit drugs and the environment-a review. Sci Total Environ. 2012.

27. US DEA. Guidelines for law enforcement for the cleanup of clandestine drug laboratories Drug Enforcement Administration (US DEA)-U.S. Department of Justice. 2005.

28. Hannan D. Meth Labs (cover story). Prof Saf. 2005;50:24-31.

29. SOPHE. Helping Communities Combat Clandestine Methamphetamine Laboratories. The Society for Public Health Education (SOPHE) in conjunction with Agency for Toxic Substances and Disease Registry and The American College of Medical Toxicology. 2007.

30. Hammon TL, Griffin S. Support for selection of a methamphetamine cleanup standard in Colorado. Regul Toxicol Pharmacol. 2007;48:102-14.

31. Skeers VM. Illegal methamphetamine drug laboratories: a new challenge for environmental health professionals. J Environ Health. 1992;55:6-10.

32. Burgess JL, Barnhart S, Checkoway H. Investigating clandestine drug laboratories: adverse medical effects in law enforcement personnel. Am J Ind Med. 1996;30:488-94.

33. Burgess JL, Chandler D. Clandestine drug laboratories. Environ Toxicol. 646-665.

34. ADEC. Guidance and standards for cleanup of illegal drugmanufacturing sites. Alaska: Alaska Department of Environmental Conservation. 2007.

35. Horton D, Berkowitz Z, Kaye W. The acute health consequences to children exposed to hazardous substances used in illicit methamphetamine production, 1996-2001. J Child Health. 2003;1:99-108.

36. Witter RZ, Martyny JW, Mueller K, Gottschall B, Newman LS. Symptoms experienced by law enforcement personnel during methamphetamine lab investigations. J Occup Environ Hyg. 2007;4:895-902.

37. Australian National Drug Strategy. National Drug Strategy 2010-2015: a framework for action on alcohol, tobacco and other drugs. The National Drug Strategy. 2011.

38. Newell P, Hugel J, Vallely P, Wright J, Makin S, et al. Clandestine Drug Laboratory Remediation Guidelines. 2011.

39. Health WA. Clandestine drug laboratories. Western Australia: Western Australia-Department of Health; 2013.

40. WA Health. Interim Guidelines for Notification and Risk Management after Detection of a Clandestine Drug Laboratory (Clan Lab). Western Australia: Western Australia-Department of Health. 2012.

41. Victoria Department of Health. Clandestine Laboratory remediation: environmental health practice note. Victoria: Victoria Department of Health. 2012.

42. Queensland Health. Advice to owners of properties where an illicit drug laboratory has operated. Queensland Department of Health. 2012.

43. NCEPH. Australian Drug Markets Research: What are we doing? Where are we going? What are the gaps? In: Proceedings of a one-day workshop; 1993 Monday 22 February 1993; Scarth Room, University House, The Australian National University. National Centre for Epidemiology and Population Health (NCEPH). 